\title{
PEMETAAN DAERAH RAWAN LONGSOR BERBASIS GIS DI KOTA BATU
}

\author{
Addi Wafa, Ely Setyo Astuti \\ Teknik Informatika, Teknologi Informasi, Politeknik Negeri Malang. \\ adiwafa@gmail.com
}

\begin{abstract}
Abstrak
Kota Batu terletak didaerah pegunungan dan ditetapkan oleh Badan Nasional Penanggulangan Bencana (BNPB) Jawa Timur sebagai daerah perbukitan yang rawan longsor. Tanah Longsor tidak dapat dicegah secara pasti namun kita dapat melakuakan upaya untuk meminimalisir terjadinya tanah longsor pada daerah rawan longsor. Tanah longsor di Kota batu dapat menggangu kelancaran mobilitas dan merugikan masyarakat karena akses mobilitas atau jalan disana terdiri dari lereng dan bukit yang terjal. Adanya pemetaan pada daerah rawan longsor akan membantu untuk meminimalisir terjadinya tanah longsor. Dari permasalahan diatas saya sebagai penulis ingin mengambil judul Pemetaan Daerah Rawan Longsor Berbasis GIS Di Kota Batu untuk membantu masyarakat secara update mengetahui dan mengawasi daerah yang dijadikan titik rawan longsor agar dapat meminimalisir jatuhnya korban dan kerugian yang banyak ketika terjadi tanah longsor dengan menggunakan metode SMART (Simple Multi Attribute Rating Technique) untuk menentukan tingkat status daerah rawan
\end{abstract}

Kata kunci : (GIS) geographic information system, Kota Batu, (SMART) Simple Multi Attribute Rating Technique, Daerah Rawan Longsor

\section{Pendahuluan}

Kota Batu terletak di daerah pegunungan diantaranya adalah Gunung Panderman (2010 m), Gunung Welirang (3156 m), Gunung Arjuno (3339 m) dan ditetapkan oleh Badan Nasional Penanggulangan Bencana (BNPB) Jawa Timur sebagai daerah perbukitan yang rawan longsor. Tanah Longsor tidak dapat dicegah secara pasti namun kita dapat melakuakan upaya untuk meminimalisir terjadinya tanah longsor pada daerah rawan longsor. Tanah longsor di Kota batu dapat menggangu kelancaran mobilitas dan merugikan masyarakat karena akses mobilitas atau jalan disana terdiri dari lereng dan bukit yang terjal. Adanya pemetaan pada daerah rawan longsor akan membantu untuk meminimalisir terjadinya tanah longsor.

Seiring dengan perkembangan zaman dan kemajuan teknologi saat ini kita dapat memetakan suatu daerah dengan ketelitian yang kita inginkan menggunakan perangkat yang saat ini sudah banyak dipergunakan yaitu GIS (Geographic Information System) atau di Indonesia sendiri lebih dikenal dengan SIG.

Dari permasalahan diatas saya sebagai penulis ingin mengambil judul Pemetaan Daerah Rawan Longsor Berbasis GIS Di Kota Batu untuk membantu masyarakat secara update mengetahui dan mengawasi daerah yang dijadikan titik rawan longsor agar dapat meminimalisir jatuhnya korban dan kerugian yang banyak ketika terjadi tanah longsor dengan menggunakan metode SMART (Simple Multi Attribute Rating Technique)untuk menentukan tingkat status daerah rawan.

\section{Landasan Teori}

\subsection{Tanah Longsor}

Menurut Direktorat Vulkanologi dan Mitigasi Bencana Geologi (2005) menyatakan bahwa tanah longsor boleh disebut juga dengan gerakan tanah. Didefinisikan sebagai massa tanah atau material campuran lempung, kerikil, pasir, dan kerakal serta bongkah dan lumpur, yang bergerak sepanjang lereng atau keluar lereng karena faktor gravitasi bumi.

Faktor penyebab terjadinya gerakan pada lereng juga tergantung pada kondisi batuan dan tanah penyusun lereng, struktur geologi, curah hujan, vegetasi penutup dan penggunaan lahan pada lereng tersebut yang dijadikan satu dengan tanda rawan erosi, namun secara garis besar dapat dibedakan sebagai faktor alami dan manusia. Menurut Direktorat Vulkanologi dan Mitigasi Bencana Geologi (2005)

\subsection{Kota Batu}

Kota Batu merupakan kota yang berdiri pada tahun 2001 sebagai pemekaran dari Kabupaten Malang yaitu dengan dasar hukum UU No. 11/2001 tertanggal 21 Juni 2001. Sebelumnya wilayah Kota Batu merupakan bagian dari Sub Satuan Wilayah Pengembangan 1 (SSWP 1) Malang Utara.

Secara astronomis Kota Batu terletak pada posisi $112^{\circ} 17^{\prime} 10,90^{\prime \prime}$ - 122 $57^{\prime} 11^{\prime \prime}$ Bujur Timur dan $7^{\circ} 44^{\prime} 55,11^{\prime \prime}-8^{\circ} 26^{\prime} 35,45$ Lintang Selatan. 


\subsection{Sistem Informasi Geografis}

Sistem informasi geografis adalah sistem berbasis komputer untuk menangkap, menyimpan, mengecek, mengintegrasikan, memanipulasi, dan mendisplay data dengan peta digital (Turban, 2005)

Sistem Informasi Geografis (SIG) atau juga dikenal sebagai Geographic Information System (GIS) pertama pada tahun 1960 yang bertujuan untuk menyelesaikan permasalahan geografis.

\subsection{Metode SMART}

Metode SMART (Simple Multi Attribute Rating Technique) merupakan metode pengambilan keputusan multi kriteria yang dikembangkan oleh Edward pada tahun 1977. Teknik pengambilan keputusan multi-kriteria ini digunakan untuk mendukung pembuat keputusan dalam memilih antara beberapa alternative, alternatif tersebut didasarkan pada teori bahwa setiap alternatif terdiri dari sejumlah kriteria yang memiliki nilai - nilai, dan setiap kriteria memiliki bobot yang menggambarkan seberapa penting ia dibandingkan dengan kriteria lain.

Pembobotan ini digunakan untuk menilai setiap kriteria agar diperoleh alternatif terbaik. Dalam mengolah data kita menggunakan Metode SMART (Simple Multi Attribute Rating Technique). Adapun teknik atau langkah-langkah dalam proses SMART, antara lain :

1. Identifikasi user yang nantinya bertanggung jawab dalam mengambil keputusan.

2. Identifikasi permasalahan yang ada dengan melihat akar permasalahan dan batasanbatasan yang ada agar nantinya tidak menyimpang dari tujuan yang ingin dicapai.

3. Identifikasi alternatif yang ada untuk mencapai tujuan dari sistem yang akan dibuat.

4. Identifikasi kriteria-kriteria yang akan mendukung pengambilan keputusan

5. Memberikan peringkat atau bobot untuk setiap kriteria. Pemberian peringkat atau bobot ini ditentukan oleh user.

6. Memberikan penilaian setiap kriteria untuk setiap alternatif. Juga dilakukan oleh user dimana penilaian setiap kriteria dapat bersifat kualitatif maupun kuantitatif untuk setiap alternatifnya.

7. Mengembangkan Single-Atribute Utilities yang mencerminkan seberapa baik setiap alternatif dilihat dari setiap kriteria.

8. Untuk mengerjakan metoode ini menggunakan Rumus dibah :

$$
\mathrm{NK}=\frac{\sum_{i=1}^{n}(\mathrm{~K}) x B B T \%}{n}
$$

Nilai akhir $=\frac{\sum n k}{n}$

$$
\begin{aligned}
& \text { Keterangan : } \\
& \begin{array}{ll}
\mathrm{NK} & =\text { Nilai Kriteria } \\
\mathrm{K} & =\text { kriteria } \\
\mathrm{n} & =\text { bayak kriteria } \\
\mathrm{BBT} & =\text { bobot }
\end{array}
\end{aligned}
$$

\section{Metodologi}

\subsection{Tahapan Penelitian}

Pembangunan sistem penelitian ini menggunakan metode waterfall. Dalam pengembangannya metode waterfall memiliki beberapa tahapan yang runtut: requirement (analisis kebutuhan), design sistem (system design), Coding \& Testing, Penerapan Program, pemeliharaan.

\section{Perancangan Sistem}

\subsection{Gambaran Umum}

Gambaran secara umum sistem informasi berbasis geografis atau yang lebih dikenal GIS yaitu sistem informasi yang didalamnya memuat peta (dalam penelitian ini yaitu peta Batu) untuk pihak BPBD sebagai media informasi daerah rawan longsor. Dibawah ini adalah gambaran jalanya sistem informasi geografi.

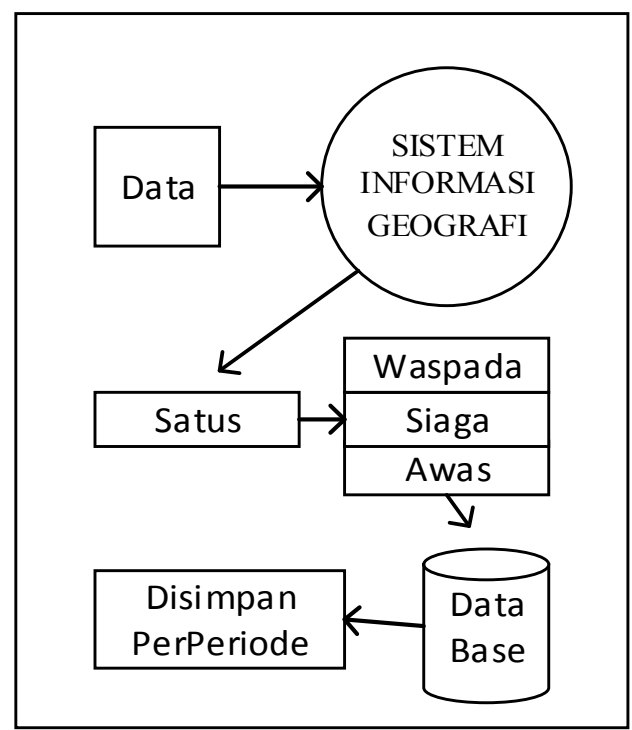

Gambar 1. Diagram Alur Sistem 


\section{Pengujian}

\subsection{Pengujian Metode}

\begin{tabular}{|c|c|c|c|c|c|}
\hline \multicolumn{6}{|c|}{ Desa Tlengkung } \\
\hline NO & Kriteria Tanah & Nilai & Bobot & NK = Nilai x Bobot & $\mathrm{NA}=$ = jlm NK : banyak kriteria \\
\hline 1 & Ringan & 15 & $20 \%$ & 3 & \multirow{4}{*}{13,4} \\
\hline 2 & Agak Berat & 12 & $40 \%$ & 4,8 & \\
\hline 3 & Berat & 63 & $60 \%$ & 37,8 & \\
\hline 4 & Sangat Berat & 10 & $80 \%$ & 8 & \\
\hline 1 & Riwayat longsor & 100 & $40 \%$ & 40 & 40 \\
\hline & & & & Status: & 26,7 \\
\hline
\end{tabular}

Gambar 2. Metode SMART

Keterangan dari gambar diatas yaitu :

1. Kolom bertulis "Desa Tlengkung" yaitu data dari Daerah Desa Tlengkung

2. Ada dua kriteria yg digunakan yaitu Kriteria Kemiringan Tanah yang terdiri dari Ringan, Agak berat, Berat dan Sangat Berar. Dan untuk Kriteria Riwayat longsor.

3. Nilai dari ktiteria Kemiringan tanah adalah persen $(\%)$ terdiri dari Ringan $=$ 15 , Agak berat $=12$, Berat $=63$, sangat berat $=10$. Nilai Dari Kriteria Riwayat tanah Longsor berisikan nilai "pernah" dan "tidak ada" untuk penilaianya "pernah" = 100 dan "Tidak Ada =0", riwayat longsor di desa Tlengkung ini adalah "Pernah" yaitu bernilai 100 .

4. Pemberian bobot setiap nilai kriteria yaitu Ringan $/$ normal $=20 \%$, Agak Berat $=40 \%$, Berat $60 \%$, Sangar Berat $=$ $80 \%$ dan untuk riwayat longsor $=40 \%$.

5. Alternatir yang dicapai yaitu Status. Ada tiga Status yaitu Waspada, Siaga dan Awas. Nilai dari Status yaitu Waspada 010, Siaga 11-30, dan Awas 31-50. Data yang dihitung menunjukan Status Waspada

\subsection{Pengujian Sistem}

Dibawah ini Sistem informasi Pemetaan daerah rawan longsor kota Batu

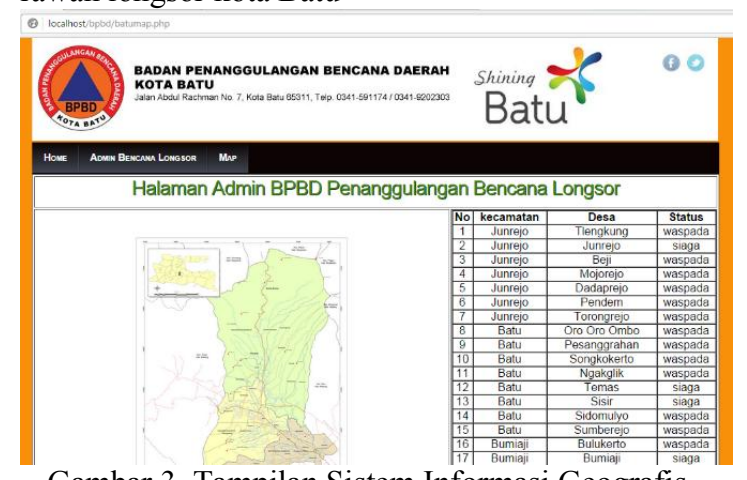

Gambar 3. Tampilan Sistem Informasi Geografis

\section{Kesimpulan dan Saran}

\subsection{Kesimpulan}

Berdasarkan penelitian yang telah dilakukan pada Pemetaan Daerah Rawan Longsor Berbasis Gis Di Kota Batu dapat diambil beberapa kesimpulan sebagai berikut :

a. Sistem Informasi Geografis ini Digunakan untuk mengolah data Badan Penanggulangan Bencana Daerah (BPBD) kota Batu tentang daerh rawan longsor

b. Sistem informasi Geografis ini sebagai jembatan informasi pada masyarakat umum untuk mengetahui kondisi daerah rawan bencana longsor

c. Dalam Penerapan Metode SMART (Simple Multi Attribute Rating Technique) membantu dalam menentukan daerah rawan longsor tiap daerah

\subsection{Saran}

Penelitian ini dapat di kembangkan pada bagian data spasial atau bagian map online-nya. Admin atau pihak BPBD dapat mengambangkan bagian pengolahan data map mulai dari tampilan map, tambah daerah, dan mengubah pemetaan.

\section{Daftar Pustaka:}

[DVMBG] Direktorat Vulkanologi dan Mitigasi Bencana Geologi. 2005. Manajemen Bencana Tanah Longsor. http://www/pikiranrakyat.com/cetak/2005/0305/22/0802.htm (25 Januari 2015)

Dwiyanto, JS. 2002. Penanggulangan Tanah Longsor dengan Grouting. Pusdi Kebumian LEMLIT UNDIP, Semarang.

Jogiyanto Hartono, H.M.,2000, Pengenalan Komputer, Andi, Yogyakarta.

Kadir, Abdul 2002, Pengenalan Sistem Informasi, Andi, Yogyakarta

Prahasta, Eddy, 2002, Konsep-konsep Dasar SIG, Informatika, Bandung.

Sitorus, Santun R. P. 2006. Pengembangan Lahan Berpenutupan Tetap Sebagai Kontrol Terhadap Faktor Resiko Erosi dan Bencana Longsor. Direktorat Jenderal Penataan Ruang Departemen Pekerjaan Umum. Jakarta.

Sri Kusumadewi, (2002). Analisis dan Desain Sistem Fuzzy menggunakan Tool Box Matlab, edisi pertama. Penerbit Graha Ilmu, Jakarta.

Tribunnews,

http://www.tribunnews.com/regional/2014/12/2 0/tujuh-sungai-rawan-banjir-dan-22-bukit-dijatim-rawan-longsor (25 Januari 2015) 